\title{
Fetichismo da técnica e geração de valor no trabalho do profissional em saúde
}

\author{
Fillipe Manoel Santos Cavalcanti ${ }^{1}$ \\ https://orcid.org/0000-0002-5624-4587
}

\author{
Maria Virgínia Borges Amaral ${ }^{2}$ \\ https://orcid.org/0000-0002-6112-984X
}

${ }^{1}$ Universidade Federal de Alagoas, Programa de Pós-graduação em Linguística e Literatura, Maceió, AL, Brasil

${ }^{2}$ Universidade Federal de Alagoas, Departamento de Serviço Social, Programa de Pós-graduação em Linguística e Literatura, Maceió, AL, Brasil

\section{Fetichismo da técnica e geração de valor no trabalho do profissional em saúde}

Resumo: Este artigo analisa o processo de determinação capitalista de produção de mais valor no trabalho do profissional em saúde, em sua articulação constitutiva com o fetiche da técnica. O presente estudo demonstrou que o trabalho dos profissionais em saúde no capitalismo é convertido numa mercadoria, cuja finalidade é a geração de mais valor a partir dos serviços de saúde. Viu-se que o processo de geração de valor do trabalho nesse campo conforma-se aos parâmetros de atendimento das demandas de reprodução do capital e necessita de um centralismo fetichizado sobre o conjunto de técnicas que compõem tal setor. Demonstra-se, assim, com este estudo, que o tecnicismo, materializado no profissional em saúde, contribui com a exploração de mais-valia relativa e de conformação ideológica alinhada aos interesses da classe dominante na sociedade do capital.

Palavras-chave: Tecnicismo. Teoria do Valor. Materialismo Histórico.

\section{Technique fetishism and value production in the health professional's work}

Abstract: This assay analyses the process of capitalist determination producing high-value in the work of the health professional, in its constitutive articulation with the fetish of the technique. The present study demonstrated that the work of health professionals in capitalism is converted into a commodity, the purpose of which is to produce high-value from health services. It was realized that the process of production value on work in this field, conforms to the parameters to achieve the demands of capital reproduction and requires a fetishized centralism about the set of techniques that compose this sector. Thus, it is demonstrated with this study that the technicality of the health professional contributes to the exploration of relative high-value and ideological conformation aligned with the interests of the dominant class in the capital society.

Keywords: Technicality. Value theory. Historical materialism

Recebido em 29.03.2020. Aprovado em 06.04.2020. Revisado em 25.05.2020.

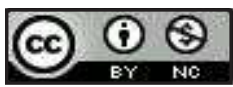

(C) O(s) Autor(es). 2020 Acesso Aberto Esta obra está licenciada sob os termos da Licença Creative Commons

Atribuição-NãoComercial 4.0 Internacional (https://creativecommons.org/licenses/by-nc/4.0/deed.pt_BR), que permite copiar, distribuir e reproduzir em qualquer meio, bem como adaptar, transformar e criar a partir deste material, desde que para fins não comerciais e que você forneça o devido crédito aos autores e a fonte, insira um link para a Licença Creative Commons e indique se mudanças foram feitas. 


\section{Introdução}

O reconhecimento, com repercussões políticas e econômicas, dos trabalhadores em saúde, " e aqui a referência é, fundamentalmente, os trabalhadores com formação escolar de nível superior, " se expressa, basicamente, em duas instâncias indissociáveis: uma social, diretamente ligada ao cotidiano da população em virtude da necessidade imediata, individual e coletiva, para com os cuidados de saúde; a outra legal, caracterizada pela institucionalização da ação desses profissionais por meio de decretos: os que tratam do direito ao trabalho no campo da saúde e os que definem os princípios éticos e políticos para esses trabalhadores atuarem, implicando a formação profissional por meio de um currículo previamente estabelecido com vistas a atender a demandas sociais e mercadológicas.

Quando se trata da instância legal do reconhecimento, cabe lembrar a Resolução no 218 , de 06 de março de 1997, definida pelo Plenário do Conselho Nacional de Saúde (CNS), em Sexagésima Terceira Reunião Ordinária, realizada nos dias 05 e 06 de março de 1997. Esse Plenário recorreu às competências e atribuições que lhe foram conferidas pela Lei $n^{\circ} 8.080$, de 19 de setembro de 1990, e pela Lei $\mathrm{n}^{\circ} 8.142$, de 28 de dezembro de 1990, para "reconhecer como profissionais de saúde de nível superior as seguintes categorias", diz: 1. Assistentes Sociais; 2. Biólogos; 3. Profissionais de Educação Física; 4. Enfermeiros; 5. Farmacêuticos; 6. Fisioterapeutas; 7. Fonoaudiólogos; 8. Médicos; 9. Médicos Veterinários; 10. Nutricionistas; 11. Odontólogos; 12. Psicólogos; e 13. Terapeutas Ocupacionais (Ministério da Saúde, 1997).

Além de reconhecer as mencionadas categorias como profissionais de saúde, o CNS, nessa mesma Resolução, reforça em suas considerações a concepção de saúde como direito de todos e dever do Estado; corrobora a compreensão de que o processo saúde/adoecimento está relacionado à condição de vida e de trabalho, colocando como uma questão fundamental para a integralidade da atenção à saúde e a participação social o acesso igualitário de todos aos serviços de promoção e recuperação da saúde. Nessa linha de considerações para enquadrar os profissionais da saúde em categorias, reafirmou a importância do Sistema Único de Saúde (SUS); "a importância da ação interdisciplinar no âmbito da saúde; e o reconhecimento da imprescindibilidade das ações realizadas pelos diferentes profissionais de nível superior [...]" (MINISTÉRIO DA SAÚDE, 1997).

Para este estudo, em virtude de experiências investigativas que temos realizado acerca do trabalho de profissionais em saúde com formação superior ${ }^{1}$, propõe-se uma análise com foco no trabalho da enfermeira. Mas ao adentrar em aspectos supostamente específicos desse campo profissional, como é o caso de uma formação tecnicista, percebe-se que embora pareça uma particularidade do trabalho da enfermeira, é, na verdade, uma característica da profissionalização da saúde: sobressair-se a técnica na formação e na prática profissional.

Muitos estudos atêm-se à bipolaridade que se expressa na realidade "o singular e o universal. Contudo, na perspectiva de análise em que se ancorou a investigação cujo resultado está exposto neste artigo; a particularidade ${ }^{2}$ une os dois extremos, singularidade e universalidade; é a categoria dialética que "une, na diferença, realidade e pensamento" (AMARAL, 2016, p. 53). A formação tecnicista da qual trata este estudo é um desses pontos que, na sociedade capitalista, em que impera o pragmatismo, produz um efeito singular de ação imediatista, simulando evidências de universalização do saber e da ação. A formação tecnicista impõe-se como uma condição do trabalho de profissionais da saúde para a geração de valor face às determinações e consequências ideológicas do tecnicismo. A mediação, ou particularidade, entre a singularidade "o ser de um trabalho em saúde " e a universalidade " a categoria dos trabalhadores em saúde - seria silenciada por esse discurso da formação tecnicista. Propõe-se, pois, a partir do trabalho de um profissional (no caso deste estudo, frisemos, a enfermeira) do grupo categorizado pela referida Resolução n $^{\circ}$ 218, de 06 de março de 1997, analisar os efeitos desse princípio tecnicista, que se constitui um tema transversal em todos os processos de formação profissional dos trabalhadores da saúde nesta sociedade sob o controle do capital.

\section{Geração de valor e o trabalho da enfermeira}

Assim como todos os profissionais categorizados pelo CNS na Resolução citada, o profissional de saúde se situa em nível educacional superior. Essa condição permite a tal profissional exercer, simultaneamente, as funções gerenciais e assistenciais do trabalho de enfermagem (SANTOS; MELO, 2019). Evidencia-se uma discrepância entre as funções exercidas por essa classe profissional e o salário pago pelo seu trabalho, sobretudo se considerada a geração do valor pelo trabalho em saúde na produção capitalista, sob um amplo processo de precarização desse trabalho.

É importante destacar que apesar dessa discrepância ser expressão da realidade objetiva no trabalho das enfermeiras, um silenciamento ${ }^{3}$ é materializado no discurso dessas profissionais: as queixas e as pautas políticas de luta são organizadas e acomodadas dentro do horizonte de reprodução da sociedade do capital. Tais 
ações são revestidas de aspectos políticos eleitorais, gerenciais e legais, produzindo efeitos de justificativas da condição de precarização do trabalho. A superficialidade e a imediaticidade com que é tratada a questão não permitem a essas trabalhadoras alcançarem as determinações da reprodução de capital que incidem no processo de exploração do seu trabalho: a geração de mais valor e de trabalho não pago.

Apesar de constituir, em termos numéricos, a maior força de trabalho em saúde no Brasil, com mais de 2 milhões de trabalhadoras (CONSELHO FEDERAL DE ENFERMAGEM, 2019), a força política da enfermagem não reflete seu quantitativo de pessoas, sendo esta uma das consequências do tecnicismo historicamente constituído e prevalente na formação e na atuação desta categoria profissional. Embora sejam plausíveis as iniciativas escolásticas de muitas teorizações sobre o aspecto tecnicista do trabalho da enfermeira ao longo do século XX e início do século XXI, também é perceptível o fortalecimento desse aspecto, nos processos produtivos e educacionais, decorrente das exigências que a sociedade capitalista impõe à formação da enfermeira.

Assim, pode-se dizer que, como os demais trabalhadores da saúde, a enfermeira trabalha para alcançar uma finalidade previamente determinada pelos interesses da sociedade. O trabalho da enfermeira se constitui numa ação teleológica (intencionalmente orientada a um fim) que, em meio ao seu processo, materializa produtos que possuem utilidade para o consumo humano ${ }^{4}$, contribuindo para a produção e reprodução da vida humana em sociedade. Trata-se de um trabalho que se complexifica pela sua imaterialidade - um trabalho imaterial (consumido no ato) -, tendo como objeto o corpo socialmente referenciado (MENDES-GONÇALVES, 2017).

Com isso, está-se considerando nesta discussão que as formas de valor do trabalho da enfermeira e seus derivados são intimamente determinados e relacionados às formas com que historicamente a humanidade organiza materialmente sua reprodução. A enfermagem é uma prática social voltada ao atendimento de demandas específicas postas historicamente nesta sociedade. Isso nos conduz ao entendimento de que as determinações contemporâneas do valor do trabalho de enfermagem são relativas ao processo de reprodução do capital. Em sua determinação mais profunda, "[...] o sistema do capital é orientado para a expansão e

O tecnicismo, no sistema de capital, é uma condição fundante dos processos econômicos; é uma das formas que determina $\mathrm{e}$ orienta o trabalho nesse tipo de sociedade; é a expressão sintética e madurecida da atual divisão social e técnica do trabalho. movido pela acumulação" (MÉSZÁROS, 2002, p. 100). A irresistível e irrefreável razão de ser do capital é reproduzir-se. A condição fundamental para essa reprodução é a produção de mercadoria. Marx (2013, p. 58) confere que o capital é irrealizável sem a produção e a circulação de mercadorias. Nesse processo, a produção de coisas com utilidade para o consumo humano (portadoras de valores de uso) precisa ser subsumida à produção de valores de troca, implicando, segundo Marx, uma relação quantitativa de troca "entre valores de uso de espécies diferentes, [...], relação que muda constantemente no tempo e no espaço". Então, nesse processo de circulação de mercadoria configurado pela troca de valores tem-se uma relação social identificada como capital. O capital, conforme entende Marx (2013), é uma relação social que se sustenta na subordinação do trabalho à sua necessidade de reprodução. Trabalho vivo transformado em capital e consequentemente convertido em trabalho morto, acumulado e alienado ao sujeito que trabalha.

No trabalho da enfermeira, a imposição do capital ao trabalho determina a razão da necessidade desse profissional. Esse trabalho é requisitado em tempos e espaços diferentes, tanto é incorporado no cotidiano da população por meio das políticas públicas de saúde realizadas no setor de serviços, como é solicitado a agir em ocasiões específicas que acometem essa população, como é o caso das pandemias ou do agravamento das condições insalubres dos centros urbanos industriais em que vive parte da população produtiva. Mas, também, é o capital que disponibiliza os meios e o acesso ao saber científico para que esse trabalhador realize a sua atividade profissional. É dessa forma que se pode entender a enfermagem como uma prática da sociedade capitalista que se realiza, em todas as suas instâncias, sob as determinações do capital. Ao atender tais demandas, o trabalho da enfermeira é convertido em mercadoria, porque produz mais trabalho; fortalece a circulação da força de trabalho no processo produtivo, intervindo na condição de saúde (ou de doença) do trabalhador para a reprodução do capital. Cabe, então, dizer, a partir do entendimento de Mendes-Gonçalves (2017), que o trabalho da enfermeira, ao ser integrado ao setor de serviços, gera mais valor, basicamente, de três formas: (1) recuperação e manutenção da força de trabalho; (2) geração de mais valor por seus próprios trabalhadores; e (3) geração de demanda para consumo. 
Cumpre lembrar que a expressão do valor do trabalho da enfermeira - mercadoria que se troca por dinheiro (salário) - não revela seu preço, mas seu valor, uma vez que o preço de uma mercadoria é a denominação monetária do trabalho objetivado nela mesma (MARX, 2013). Assim, o papel da monetarização, enquanto coeficiente que regula e iguala o valor das mercadorias, permite a discrepância entre a capacidade da força de trabalho em produzir valor e o valor monetarizado dessa força. Em termos monetários, o valor precificado da força de trabalho da enfermeira é, quase sempre, menor que o valor gerado por essa força no processo de trabalho.

A seguir, situa-se o ponto fundamental de codeterminação entre o processo de produção de mais-valia e o fetiche da técnica: o tecnicismo é uma força indispensável na ampliação da extração de mais-valia, pois faz aumentar, na mesma carga horária, a produção de bens e serviços por uma determinada força de trabalho. $\mathrm{O}$ tecnicismo possibilita ao capitalista, dessa maneira, aumentar sua lucratividade, ao pagar a mesma quantia monetária por uma mercadoria que é capaz de gerar ainda mais valor, assim como entende Marx (2013) ao tratar sobre a extração de mais-valia relativa.

\section{A fetichização da técnica e suas bases materiais}

O tecnicismo é uma forma particular de fetiche. Sua caracterização específica se dá pela fetichização da técnica no processo de reprodução social. Entende-se que no desenvolvimento do capitalismo a atividade econômica é um complexo predominante entre os outros complexos sociais e a técnica é um "momento parcial do desenvolvimento econômico", não é um momento predominante; não é "um fatum autônomo e insuperável da Era Moderna" (LUKÁCS, 2013, p. 260). Nesse ponto da história da sociedade do capital, incorre-se na fetichização da técnica; há o simulacro da predominância da técnica, o predomínio do tecnicismo, assim como as táticas e estratégias, no desenvolvimento econômico e, consequentemente, na manutenção do status quo do capitalismo. Cumpre dizer que a importância da técnica está atrelada ao processo de reprodução social. Lukács (2013, p. 262) explicita que, “Assim como na própria economia, a técnica é parte importante, mas sempre apenas derivada do desenvolvimento das forças produtivas, sobretudo dos homens (do trabalho), das relações interpessoais (divisão do trabalho, estratificação de classe etc.)".

Nessa linha de reflexão entende-se que a fetichização da técnica produz um efeito de silenciamento no trabalho. A evidência de automação da técnica criada na sociedade capitalista dos tempos atuais busca separar a realidade do pensamento, implicando na limitação da capacidade de conhecer e entender a complexidade do trabalho nesta sociedade.

É importante dizer que a importância da técnica está em satisfazer necessidades humanas, otimizar o processo de trabalho e aumentar sua produtividade. Por isso, não se trata de uma abordagem negativista ao desenvolvimento e ao aperfeiçoamento técnico, ou de desprezar a sua importância, mas de "[...] afastar do cérebro dos homens o fatalismo fetichizado e mostrar que a técnica foi sempre e apenas um meio no desenvolvimento das forças produtivas, que as forças produtivas, em última análise, são sempre os homens e suas capacidades [...]" (LUKÁCS, 2014, p. 71).

A forma fetichizada da técnica é caracterizada por sua capacidade de produzir estranhamento: a técnica, ao se tornar uma força alienada, projeta-se para fora do ser que a desenvolve (exterioriza-se) e se volta contra ele, como uma força hostil que o controla. Esse processo de alienação, decorrente do fetichismo, inverte a ordem ontológica do processo. Agora o criador (o ser, no processo de trabalho) perde o controle sobre sua criação (a técnica) e os destinos deste ser e do trabalho social passam a depender do movimento autônomo das técnicas. Estas, agora, assumem poderes fantasmagóricos sobre o trabalho e sobre as pessoas. O trabalho humano social, desta feita, tende a ser controlado pela determinação estranhada da técnica.

O fetiche da técnica produz um efeito de deslocamento da finalidade do instrumento na atividade produtiva: não é o trabalhador que usa a técnica para seus fins, mas a técnica se apropria do trabalhador e o domina, fazendo dele um agente do tecnicismo. Na produção capitalista, trabalhadores se tornam extensões da técnica, meios de sua realização, e se subordinam ao seu movimento, em obediência a uma finalidade que lhe é estranha. O tecnicismo consiste, portanto, na criação de um reflexo subjetivo que cria uma pseudorrealidade, na qual as características sociais da atividade humana são transferidas e ressignificadas como propriedades naturais sociais das técnicas e, por isso, também refletem a relação social dos produtores com seu trabalho como algo que existe fora deles, apenas entre técnicas.

O poder fantasmagórico do tecnicismo não é, todavia, da ordem do espírito, mas advém da ordem material galgada na forma com que os homens se relacionam enquanto produtores. Nesse sentido, entende-se que há de se buscar a função social do tecnicismo na sociedade do capital. A necessidade do capital que requisita o fetichismo da técnica é a de criar uma realidade apartada do pensamento, da crítica à essa realidade, e em detrimento das necessidades humanas, na qual a centralidade do produto social do trabalho esteja 
associada à racionalidade utilitarista e imediata da técnica na produção (direta e indireta) de mercadorias em formas compatíveis com os parâmetros estruturais do sistema do capital.

No capitalismo, existem duas razões complementares e articuladas que requisitam esse fetiche: uma econômica e outra ideológica. O motivo econômico da necessidade do tecnicismo no sistema do capital vem da condição de que a (re)produção de mais-valia é a lei absoluta do modo de produção capitalista (MARX, 2013). Em sua determinação mais profunda, "[...] o sistema do capital é orientado para a expansão e movido pela acumulação" (MÉSZÁROS, 2002, p. 100).

Como a necessidade de reprodução e acumulação sempre crescente é imperativa e não alternativa, a centralidade do processo social precisou voltar-se para a crescente produção-circulação-consumo de mercadorias, forma clássica de realização do capital. O capital precisa subordinar os vários complexos à garantia de sua reprodução econômica; precisa se constituir como uma forma de controle de abrangência totalizadora, de modo que a educação, a política, a arte, o direito e a enfermagem, em meio às suas autonomias relativas, se alinham aos parâmetros estruturais do sistema. Nesse sentido, "[...] o modo de operação do sistema do capital é a exceção e não a regra, no que diz respeito ao intercâmbio produtivo dos seres humanos com a natureza e entre si" (MÉSZÁROS, 2002, p. 96).

Decorre desse modus operandi uma das novidades históricas do sistema do capital em relação aos seus antecessores históricos: a perda de controle sobre os processos de tomada de decisão decorrente da separação imperativa e negativa entre produtores e a totalidade do processo produtivo. De fato, o capital é uma relação que escapa a qualquer controle adequado duradouro ou a uma autorrestrição racional, e precisa ser assim (!), pois essa incontrolabilidade é a base para a possibilidade de sua ascensão histórica como fundamento da produção. Assim,

ao se livrar das restrições subjetivas e objetivas da autossuficiência, o capital se transforma no mais dinâmico e mais competente extrator do trabalho excedente em toda a história. Além do mais, as restrições subjetivas e objetivas da autossuficiência são eliminadas de uma forma inteiramente reificada, com todas as mistificações inerentes à noção de 'trabalho livre contratual'. [...] o capital ultrapassa infatigavelmente todos os obstáculos e limites com que historicamente se depara, adotando até as formas de controle mais surpreendentes e intrigantes - aparentemente em discordância com seu caráter e funcionalmente 'híbridas' - se as condições o exigirem (MÉSZÁROS, 2002, p. 103, 104, grifo do autor).

O isolamento dos produtores em produtores privados é a condição material tanto do fetiche da mercadoria quanto do fetiche da técnica. No fetiche da mercadoria, são elas próprias que se relacionam entre si, ganhando vida própria. No tecnicismo, acontece coisa semelhante: são as técnicas que se relacionam no processo de trabalho. O ser é reduzido à posição de executor dessas técnicas, que, por sua vez, tornam-se autônomas e donas de um processo entre sujeitos.

A incontrolabilidade e a orientação à expansão-acumulação fazem com que o tecnicismo desponte no capitalismo como a forma par excellence de reprodução econômica do capital, aquela que mais se alinha aos seus imperativos reprodutivos. Em outras palavras, a forma tecnicista é a mais eficaz, ou melhor, é a única forma compatível com a demanda sempre crescente de reprodução e acumulação exigida pelo capital.

Marx (1996, p. 246) explica que a composição do capital tem de ser compreendida em um duplo sentido. Primeiramente na perspectiva do valor, sendo esta " [...] determinada pela proporção em que se reparte em capital constante ou valor dos meios de produção e capital variável ou valor da força de trabalho, soma global dos salários". O segundo sentido, o da matéria (como ela funciona no processo de produção), compreende cada capital se repartindo em dois: (1) na forma de meios de produção; e (2) na forma de força de trabalho viva. A composição material do capital é, conforme Marx (1996, p. 246), determinada pela "[...] proporção entre, por um lado, a massa dos meios de produção utilizados e, por outro lado, o montante de trabalho exigido para seu emprego". Marx chamou a primeira de "composição-valor" e a segunda de "composição técnica" do capital. Dessa forma, a composição orgânica do capital é a correlação da determinação da composição-valor pela composição técnica.

Diante dessa condição, entende-se porque o tecnicismo está organicamente presente nas bases da reprodução do capital. Afinal, somente elevando a técnica a uma condição fetichizada, ou seja, a sua execução dissociada da função ontológica cada vez mais potencializada, é que podem ser produzidas mercadorias e mais valor, de acordo com as demandas necessárias ao funcionamento do sistema. O tecnicismo, então, garante a reprodução expansiva do capital, ampliando a sua composição-valor (o desenvolvimento tecnológico dos meios de produção) e a sua composição técnica (o montante de trabalho exigido para seu emprego). É essa ampliação quanti-qualitativa do capital que proporciona as variadas formas de extração da mais-valia absoluta e relativa.

O tecnicismo, desse modo, não se limita a uma tendência pedagógica ou a alguma outra forma epistemológicognosiológica. O tecnicismo, no sistema de capital, é uma condição fundante dos processos econômicos; é uma das 
formas que determina e orienta o trabalho nesse tipo de sociedade; é a expressão sintética e madurecida da atual divisão social e técnica do trabalho. As suas manifestações no trabalho em saúde, nas ciências, na política, no direito e nos outros complexos sociais são expressões da determinação dialética e ideológica da sua condição econômica original: a centralidade na técnica alienada nos processos do trabalho em detrimento da apreensão consciente da totalidade e da historicidade desse processo com a realidade social.

Mas, lembremos que a dimensão econômica do tecnicismo é apenas uma parte desse fetiche, o qual, pelo próprio fato de ser um fetiche, necessita obrigatoriamente cumprir uma função ideológica. Ressalte-se, ainda, que, apesar de apresentarmos as dimensões econômicas e ideológicas em momentos distintos, tais dimensões se dão em unidade e de forma indissociável, uma vez que toda ideologia é orientada para a prática. Dessa maneira, entende-se que as condições de produção materiais da vida são determinadas dialeticamente, entre outros complexos, pela Ideologia.

A função ideológica central do tecnicismo se assenta na necessidade que o sistema do capital tem de encontrar algum denominador comum para a dualidade, expressa em classes sociais antagônicas, decorrente da exploração do capital sobre o trabalho. Diante disso, “[...] um complicado sistema de divisão social hierárquica do trabalho deve ser superposto à divisão do trabalho funcional/técnica (e, mais tarde, tecnológica altamente integrada) como força cimentadora pouco segura [...] de todo o complexo" (MÉSZÁROS, 2002, p. 99).

O funcionamento adequado desse complicado sistema de divisão hierárquica do trabalho superposto à divisão funcional/técnica só é possível por conta da predominância da racionalidade técnica, alienada na execução do processo de trabalho. Essa centralidade se caracteriza por se comportar como uma espécie de prisão da subjetividade do ser social ao caráter técnico da execução da tarefa, de modo que as tomadas de decisão regularmente se limitam apenas às escolhas das melhores técnicas em determinado ofício. Esse proceder contribui também para o entendimento de que o suposto desenvolver das capacidades produtivas deve se limitar à descoberta de melhores técnicas, tecnologias e suas implementações. Uma vez centrado na racionalidade técnica, o trabalhador (e aqui especificamente a enfermeira, como todo trabalhador em saúde) tende a perder a capacidade de apreensão da totalidade do processo, afastando-se das tomadas de decisão, favorecendo o processo de exploração do seu trabalho pelo capital.

\section{Fetiche da técnica e produção de valor no trabalho da enfermeira}

Na história da enfermagem moderna vê-se o processo que a constitui como uma prática eminentemente tecnicista, implicando o tornar-se enquanto tal. Na incursão da enfermagem - com seu prosseguir representado pelos esforços de Florence Nightingale - na busca por uma determinada cientificidade, pode-se identificar o início do que viria a ser o seu caráter tecnicista. O predomínio da técnica no processo de consolidação do trabalho da enfermeira vai se transformando no eixo orientador do processo de cientificidade da enfermagem.

A teoria ambientalista formulada por Florence Nightingale, por exemplo, de acordo com Ericson (2019), menciona em suas proposições o humanismo na inter-relação do cuidado de enfermagem com os ambientes social, político e ecológico. Nightingale (2010), apesar de centrada nos fatores biológicos, considerava a saúde como um processo e não apenas como o estado de manifestação patológica do agravo. Outro destaque da concepção nightingaleana, que se pode lembrar aqui, é a ampliação conceitual no que se refere ao foco assistencial do trabalho em saúde: em lugar de uma assistência centrada na doença, Nightingale preconizava uma atuação centrada na pessoa doente e nas condições imediatas do ambiente (NIGHTINGALE, 2010; OGUISSO, 2007). Entretanto, essa abordagem, mesmo representando avanços significativos, ainda permanecia focada no indivíduo; e na atuação da enfermeira predominava, cada vez mais, o caráter técnico do trabalho.

Assim, o tecnicismo se expressará no trabalho da enfermeira e o conduzirá a importantes implicações. A divisão técnica do trabalho, decorrente da necessidade do capitalismo pela sua maneira alienada, implicou a criação de duas categorias distintas na enfermagem: as nurses e as lady-nurses. Conforme Ericson (2019, p. 22), "as enfermeiras ditas de cabeceira, voltadas ao trabalho manual, eram consideradas nurses (enfermeiras); já as enfermeiras que realizavam a supervisão da equipe e a gerência do serviço de enfermagem, eram chamadas lady-nurses [...]”.

No Brasil, a divisão técnica do trabalho em enfermagem se expressa em cinco categorias, sendo três oficiais e duas complementares. As divisões oficiais compreendem o trabalho da enfermeira (registram-se, hoje, no Brasil, 521.454 profissionais), auxiliar de enfermagem (uma média de 413.763 profissionais) e técnico de enfermagem (tem-se 1.206.406 profissionais). Por sua vez, as complementares englobam os Agentes Comunitários de Saúde (ACS) e os cuidadores (SANTOS; MELO, 2019).

O efeito econômico dessa divisão do trabalho, enquanto expressão do tecnicismo na enfermagem no Brasil, é o de barateamento da força de trabalho da enfermeira a partir da geração de mais valor. Vejamos: um 
profissional de nível escolar médio custa ao dono da empresa hospitalar e/ou ao Estado, uma parcela monetária (salário) consideravelmente menor que aquela paga a um trabalhador de nível de ensino superior. Com uma força de trabalho barateada, a tendência é que os custos diminuam e os lucros aumentem. Além disso, a divisão do trabalho, nesses moldes, implica uma fragmentação da atividade que impede a apreensão por parte da enfermeira do processo geral de seu trabalho. Os resultados decorrentes são as ampliações do caráter fragmentado da assistência, do tecnicismo e do estranhamento entre os entes do/no processo, distanciando cada vez mais o pensamento da realidade.

Esse tipo de fragmentação, característica de todo processo de profissionalização, já era realizado dentro dos limites da atuação profissional, e ainda mais o é em relação à reprodução social mais ampla. Não era finalidade do trabalho da enfermeira uma análise/atuação em articulação com a totalidade social ou o incentivo à participação política. A enfermagem, segundo Florence Nightingale (2010), deveria interessar-se em servir à sociedade, dentro dos limites técnicos que eram de sua competência - inclusive servindo à equipe médica.

O não questionamento das contradições sociais decorrentes da incontrolabilidade necessária ao capital é garantia do seu bom funcionamento. A técnica, ao tornar-se fetichizada, faz com que o trabalhador não tenha como prioridade a identificação das causas dos problemas com os quais lida no seu cotidiano de trabalho; não conhece o movimento do capital e suas contradições estruturais. Com isso, o foco cairá sobre as manifestações mais fenomênicas e superficiais dos problemas (as técnicas e teorias ultrapassadas, a gerências dos recursos pelo Estado, a forma do Estado). Entendemos ser esse o momento expressivo da junção e da indissociabilidade das funções econômicas e ideológicas do tecnicismo na garantia da expansão e acumulação do capital.

Os elementos expostos permitem reposicionar o tecnicismo, não somente como um projeto de origem teórica, nascido da "iluminação" de alguns intelectuais apologéticos que descobriram a forma mais eficaz de formação da força de trabalho para as necessidades de expansão do capital, mas também como uma condição elementar básica e inevitável da própria natureza do capital, quando este se torna a relação fundamental da reprodução social. Nesse sentido, o caráter tecnicista do trabalho da enfermeira não deve ser entendido como uma série de casualidades históricas, mas como parte de um projeto histórico de dominação social orientado pela extração de mais-valia e geração de valor.

\section{Algumas considerações}

Parafraseando Pêcheux (2014), a enfermeira, como todos os trabalhadores de formação superior da saúde, não se torna tecnicista pela graça do céu. Nem tão pouco essa condição é imposta pelo sujeito Florence Nightingale, ou unicamente pela determinação positivista na busca por um modelo de cientificidade. A enfermeira torna-se tecnicista porque essa é uma necessidade imperativa do capital para o trabalho em saúde e em todos os setores de serviço com os quais contribui, direta ou indiretamente, para a geração de lucro.

Por fim, a partir da pesquisa que resultou na sistematização exposta neste artigo, pode-se dizer que o tecnicismo é uma condição ontogênica do trabalho no capitalismo, um imperativo do capital no seu processo de expansão e acumulação. Devido ao fato de ser um imperativo das necessidades de reprodução do capital, o tecnicismo não sumirá ou perderá força nos complexos da sociedade capitalista ${ }^{5}$, sobretudo o econômico. O trabalho em saúde, como o da enfermeira, enfrenta essa realidade. Mesmo com as diversas condenações escolásticas de muitas teorizações sobre o tecnicismo ao longo do século XX e início do século XXI, o mesmo continua seu predomínio real na determinação dos processos produtivos e educacionais do trabalho da enfermeira.

Desta feita, a tarefa de romper com o caráter tecnicista do trabalho da enfermeira vai muito além das críticas acadêmicas e político-formais. Ela perpassa a condição de tomar para si a luta histórica do nosso tempo: romper, em todas as suas determinações estruturais, com a sociedade do capital. Eis, de fato, o desafio.

\section{Referências}

AMARAL, M. V. B. Discurso e relações de trabalho. Maceió: Edufal, 2016.

AMARAL, M. V. B. A condição do trabalho e o serviço social no setor sucroenergético. In: AMARAL, M. V. B. (org.). Capital X Trabalho no campo: questão agrária, agricultura familiar e trabalho no setor sucroenérgetico. Maceió: EDUFAL, 2011. v. 1. p. 1-1. AMARAL, M. V. B. A volatilidade do trabalho do profissional em Serviço Social em tempos de crise. In: AMARAL, M. V. B.; AlCÂnTARA, N. (org.). Trabalho, Política, Vida Cotidiana, Serviço Social. Maceió: EDUFAL, 2015. v. 1. p. 35-54. CONSELHO FEDERAL DE ENFERMAGEM. Enfermagem em números. COFEN, Brasília, DF: 2019. Disponível em: http:// www.cofen.gov.br/enfermagem-em-numeros. Acesso em: 6 abr. 2020. 
ERICSON, S. Processos de modelização na institucionalização de saberes no campo de enfermagem. In: AMARAL, M. V. B.; ERICSON, S. Do discurso: fundamentos e práticas. Maceió: Edufal, 2019.

LUKÁCS, G. Conversando com Lukács. São Paulo: Instituto Lukács, 2014.

LUKÁCS, G. O Particular à luz do Materialismo Dialético. In: LUKÁCS, G. Introdução a uma estética Marxista. Rio de Janeiro: Civilização Brasileira, 1978.

LUKÁCS, G. Para uma ontologia do ser social. São Paulo: Boitempo, 2013.

MARX, K. O Capital: crítica da economia política. Livro 1. 31. ed. Rio de Janeiro: Civilização Brasileira, 2013.

MARX, K. O Capital: crítica da Economia Política. Livro 1. Tomo II. São Paulo: Nova Cultural, 1996.

MENDES-GONÇALVES, R. B. Saúde, sociedade e história. São Paulo: Rede Unida, 2017.

MÉSZÁROS, I. Para além do Capital. São Paulo: Boitempo, 2002.

MINISTÉRIO DA SAÚDE. Conselho Nacional de Saúde. Resolução nº 218, de 06 de março de 1997. O Plenário do Conselho Nacional de Saúde em Sexagésima Terceira Reunião Ordinária, realizada no dia 05 e 06 de março de 1997, no uso de suas competências regimentais e atribuições conferidas pela Lei n ${ }^{\circ} 8.080$, de 19 de setembro de 1990, e pela Lei n. ${ }^{\circ} 8.142$, de 28 de dezembro de 1990. [Brasília, DF]: Conselho Nacional de Saúde, 1997. Disponível em: http://bvsms.saude.gov.br/bvs/saudelegis/cns/1997/res0218_06_03_1997.html. Acesso em: 6 abr. 2020.

NIGHTINGALE, F. Anotações de enfermagem: o que é, e o que não é. Tradução Janaina Belém. São Paulo: Rideel, 2010.

OGUISSO, T. A influência francesa na enfermagem brasileira. In: OGUISSO, T. (org.). Trajetória histórica e legal da enfermagem. Barueri, SP: Manole, 2007. p. 130-158.

ORLANDI, E. As formas do silêncio no movimento dos sentidos. Campinas, Ed. da Unicamp, 1992.

PÊCHEUX, M. Semântica e Discurso: uma crítica à afirmação do óbvio. Campinas, SP: Editora Unicamp, 2014.

SANTOS, T. A. dos; MELO, C. M. M. Valor do trabalho da enfermeira. Salvador: Edufba, 2019.

\section{Notas}

1 É o caso dos estudos sobre o trabalho do Assistente Social realizados por Amaral (2011, 2015).

2 As categorias filosóficas da singularidade, universalidade e particularidade são categorias dialéticas que se manifestam na realidade histórico-social, possibilitando a condições estruturais dessa realidade e as transformando historicamente. Concebe-se essas categorias na perspectiva marxista explicitada por Lukács (1978): O particular à luz do materialismo dialético; e por Chasin (1995).

3 Silenciamento é uma expressão derivada da concepção de silêncio como instância de significação no discurso, conforme o desenvolvimento teórico desse conceito por Orlandi (1992, p. 75). Para a autora o silenciamento é uma forma de silêncio; trata-se de uma política do silêncio "que se define pelo fato de que ao dizer algo apagamos necessariamente outros sentidos possíveis, mas indesejáveis, em uma situação discursiva" (AMARAL, 2016, p. 177, nota 123).

4 Faz-se aqui referência aos atos sistemáticos de gerência, pesquisa, ensino e assistência que se destinam manutenção da vida (SANTOS; MELO, 2019).

5 Conferir-Complexo de complexos-Lukács (2013, p. 201-302).

\section{Fillipe Manoel Santos Cavalcanti}

fillipe.msv@gmail.com

Mestre em Educação pelo Programa de Pós-graduação em Educação da Universidade Federal de Sergipe (UFS)

Doutorando no Programa de Pós-graduação em Linguística e Literatura da Universidade Federal de Alagoas (UFAL)

\section{UFAL}

Campus A. C. Simões. Av. Lourival Melo Mota, S/N, Tabuleiro do Martins

Maceió - AL - Brasil

CEP: 57072-970

\section{Maria Virgínia Borges Amaral}

mvirginia39@gmail.com

Doutorado pelo Programa de Pós-graduação em Linguística e Literatura da Universidade Federal de Alagoas (UFAL)

Professora da Universidade Federal de Alagoas (UFAL) 


\section{UFAL}

Campus A. C. Simões. Av. Lourival Melo Mota, S/N, Tabuleiro do Martins

Maceió - AL - Brasil

CEP: 57072-970

\section{Agradecimentos}

Aos profissionais de saúde, em especial as enfermeiras, que lutam com suor, sangue e com a vida para cuidar dos corpos da classe trabalhadora

\section{Agência financiadora}

Não se aplica.

\section{Contribuições das autoras}

$\mathrm{O}$ artigo foi redigido por ambos autores.
Aprovação por Comitê de Ética e consentimento para participação

Não se aplica.

\section{Consentimento para publicação}

Não se aplica.

Conflito de interesses

Não há conflito de interesses. 